\title{
Spatiotemporal Distribution Pattern of Sclerotinia sclerotiorum Apothecia is Modulated by Canopy Closure and Soil Temperature in an Irrigated Soybean Field
}

\author{
Mamadou L. Fall, Department of Plant, Soil and Microbial Sciences, Michigan State University, East Lansing; Jaime F. Willbur and Damon \\ L. Smith, Department of Plant Pathology, University of Wisconsin-Madison, Madison; and Adam M. Byrne and Martin I. Chilvers, ${ }^{\dagger}$ De- \\ partment of Plant, Soil and Microbial Sciences, Michigan State University
}

\begin{abstract}
Identifying the optimal timing for fungicide application is crucial in order to maximize the control of Sclerotinia stem rot (SSR), which is caused by Sclerotinia sclerotiorum. In this study, the impact of canopy closure and soil temperature on apothecia production was investigated to optimize fungicide application timing. Replicated soybean plots with a row spacing of 0.36 and 0.38 or $0.76 \mathrm{~m}$ were established in 2015 and 2016 in an irrigated soybean field at Michigan State University's Montcalm Research Center. The number of apothecia and ascospores and the incidence of SSR were monitored two times per week for 10 to 12 weeks. In both row-spacing trials, apothecia were observed earlier in 2016 (before the $\mathrm{R} 1$ growth stage) than in 2015 (between $\mathrm{R} 1$ and $\mathrm{R} 2$ ). The maximum number of apothecia was 50 times higher with the $0.36-\mathrm{m}$ row spacing than with the $0.76-\mathrm{m}$ row spacing in 2015 but was 2.5 times higher with the $0.76-\mathrm{m}$ row spacing than with the $0.38-\mathrm{m}$ row spacing in 2016, though the overall numbers were much lower in 2016. The apothecia

distribution pattern was synchronized with the canopy closure pattern and the soil temperature profile. The peak number of apothecia was observed when canopy closure reached at least $50 \%$ and when average soil temperature in the row was between 21.5 and $23.5^{\circ} \mathrm{C}$. In $91 \%$ of the cases, the presence of apothecia was observed when the percentage of light blocked was $70 \%$, and no apothecia germinated in the absence of light or under full light exposure. During the first 50 days after plant emergence, the rate of canopy closure was higher in 2016 than in 2015, and the first diseased plant was observed earlier in 2016 (R2) than in 2015 (R5). Canopy closure and the distance of the sampling point from the soybean row explained much of the variability in the number of apothecia. These results can partially explain the inconsistent efficacy of fungicide applications based on the soybean growth stage and will be helpful for informing disease models and fine-tuning fungicide application strategies.
\end{abstract}

Sclerotinia stem rot (SSR), caused by Sclerotinia sclerotiorum (Lib.) de Bary, is a devastating disease of many crop plants and can cause significant economic losses under conducive environmental conditions, which often occur in the northern United States (Boland and Hall 1994; Peltier et al. 2012; Fall et al. 2018). In soybean (Glycine max (L.) Merr.), from 2010 to 2014, SSR remained among the top 10 most destructive diseases in the northern United States and Ontario, Canada (Allen et al. 2017; Peltier et al. 2012). S. sclerotiorum can survive as sclerotia in the soil for up to 7 years and can produce numerous aerially dispersed ascospores (up to 30 million per apothecium) from ascocarps during the growing season, infecting plants when weather conditions are favorable (Abawi and Grogan 1979; Merriman 1976). Depending on the cropping system, infection of plants can occur through hyphae directly from myceliogenic germination of sclerotia or by infected plant material that is in contact with the host plant, or through ascospores released from apothecia (Clarkson et al. 2004). Sclerotia of S. sclerotiorum germinate

Current affiliation of M. L. Fall: Agriculture and Agri-Food Canada, SaintJean-sur-Richelieu, QC, Canada.

${ }^{\dagger}$ Corresponding author: M. L. Chilvers, E-mail: chilvers@msu.edu

Funding: Funding for this study was provided, in part, by the Michigan Soybean Promotion Committee, the North Central Soybean Research Program, DuPont Crop Protection, and USDA-ARS Specific Cooperative Agreement number 58-5442-4-017 (National Sclerotinia Initiative)

*The $\boldsymbol{e}$-Xtra logo stands for "electronic extra" and indicates that one supplementary table is published online.

Accepted for publication 27 March 2018.

This article is in the public domain and not copyrightable. It may be freely reprinted with customary crediting of the source. The American Phytopathological Society, 2018. to form apothecia whenever the soil is shaded, moist, and cool (4 to $16^{\circ} \mathrm{C}$ ). Mature apothecia can discharge millions of ascospores and, when deposited on flower petals, can go on to germinate and colonize them (Abawi and Grogan 1975, 1979; Boland and Hall 1988a; Grau 1988). In soybean, senescing petals are energy sources that support infection of plants by ascospores, especially in fields with narrow row spacing, high plant populations, and a dense plant canopy. Therefore, it is crucial that the application of fungicides be timed with the flowering period (Abawi and Grogan 1975; Mueller et al. 2004; Sutton and Deverall 1983).

Some foliar-applied fungicides and herbicides show efficacy for controlling SSR in susceptible crops and cultivars (Peltier et al. 2012). Fungicides from three different chemical classes are registered for SSR control in soybean. These fungicides inhibit S. sclerotiorum infection and growth in different ways, by inhibiting cell division, cell respiration, or sterol production (Peltier et al. 2012). Herbicides such as those of the protoporphyrinogen oxidase inhibitor mode of action do not directly inhibit $S$. sclerotiorum but they can induce phytoalexins in soybean, resulting in an induced systemic response (Dann et al. 1999). Herbicide applications to soybean can also result in a modification of the canopy and delay or reduce flowering, which can lead to less conducive environmental conditions (Nelson et al. 2002) for SSR development. However, fungicides and pesticides need to be applied at the proper growth stage for maximum benefit. Mueller et al. (2004) suggested spraying at the R1 growth stage for a higher level of SSR control, whereas other disease management reports have indicated that sometimes spraying at R3 or applying one spray at R1 followed by another spray at R3 is more beneficial (Byrne and Chilvers 2014; Chilvers and Byrne 2015; Wunsch 2014). Peltier et al. (2012) noticed the inconsistent efficacy of fungicide and herbicide application and suggested that this inconsistency may be explained by the inability of fungicides to move upward and downward in plants. However, the timing of apothecia production may explain the lack of efficacy of pesticide application depending on the growth stage. In other words, the best timing for fungicide application is modulated by the conditions (biotic and abiotic) required for 
apothecia germination, which occur before or during the flowering period. In years when weather conditions are continuously conducive for apothecia production during the flowering period, multiple applications may be required, and the cost is significantly increased (Mueller et al. 2002a). However, complete control of SSR with only pesticides is not achievable and, thus, pesticides should be used as part of an integrated management system that includes crop rotation, biological control, cultivar selection, and tillage (Peltier et al. 2012).

Tillage has been shown to affect the number, viability, and distribution of sclerotia in the soil profile. Burying sclerotia seems to decrease or delay the development of apothecia outside the flowering period (Mueller et al. 2002b). However, the impact of tillage on SSR development is inconsistent (Peltier et al. 2012). Tillage systems can affect SSR incidence through their effect on soybean emergence, plant population, and canopy structure rather than their effect on apothecia production (Kurle et al. 2001). Kurle et al. (2001) found that differences in canopy density among tillage systems are more important than differences in the density of viable sclerotia affecting the number of apothecia and subsequent level of SSR incidence. As the canopy is closing, the microclimate under the canopy tends to promote sclerotial germination and SSR development by maintaining high humidity, prolonging leaf wetness, lowering temperature (Blad et al. 1978; Kurle et al. 2001), and lowering the quantity of light reaching the soil surface. Light, temperature, and moisture are considered to be the three most important factors for the germination of sclerotia of S. sclerotiorum (Abawi and Grogan 1979; Letham 1975; Sun and Yang 2000).

The objectives of our research were to (i) determine the dynamics of apothecia production, ascospore release, and SSR development under irrigated field conditions; (ii) determine the spatiotemporal distribution of S. sclerotiorum apothecia as a function of row spacing, canopy closure, and weather variables; and (iii) determine biotic and abiotic factors driving apothecia production under irrigated field conditions. Outcomes from this project will be incorporated into further refinement of an apothecia risk model that is used to advise fungicide application timing and improve SSR management (Willbur et al. 2018).

\section{Materials and Methods}

Field trials. In 2015 and 2016, field trials using the Asgrow soybean cultivar AG2535 were established at Michigan State University's Montcalm Research Center (Montcalm, MI) in TekeninkElmdale loamy sands naturally infested with $S$. sclerotiorum. In 2015, two trials were planted on 21 May, with a row spacing of either 0.76 or $0.36 \mathrm{~m}$, and each trial contained eight plots measuring $12.2 \mathrm{~m}$ long by $6.1 \mathrm{~m}$ wide. In 2016, two trials were planted on 17 May, with a row spacing of either 0.76 or $0.38 \mathrm{~m}$, and each trial contained four plots measuring $6.1 \mathrm{~m}$ long by $3.0 \mathrm{~m}$ wide. In both years, the plots were planted at a target density of 400,000 seeds/ha and were overhead irrigated, based on rainfall frequency and prior to the beginning of flowering, with 5.4 to $6.4 \mathrm{~cm}$ of water approximately once a week between 6 July and 12 August.

On each sampling day, pictures of the canopy were taken in three fixed spots at a height of $1.5 \mathrm{~m}$ in each trial. For scale reference, every picture included a plastic ruler. The fixed spots were rectangles measuring 1.22 by $1.52 \mathrm{~m}$ and were randomly selected during the experimental setup. The distance between rows was measured from the pictures using ImageJ software (Rueden et al. 2016), and the average of the distances measured in three fixed spots was considered to be the daily measured distance between rows. The percentage of canopy closure was then calculated for each sampling day as follows:

$$
\begin{aligned}
\text { Canopy closure }= & 1-(\text { daily measured distance } / \\
& \text { row spacing distance })
\end{aligned}
$$

For example, row spacing distance was 0.76 and $0.38 \mathrm{~m}$ for the 0.76- and 0.38-m row-spacing trials, respectively.
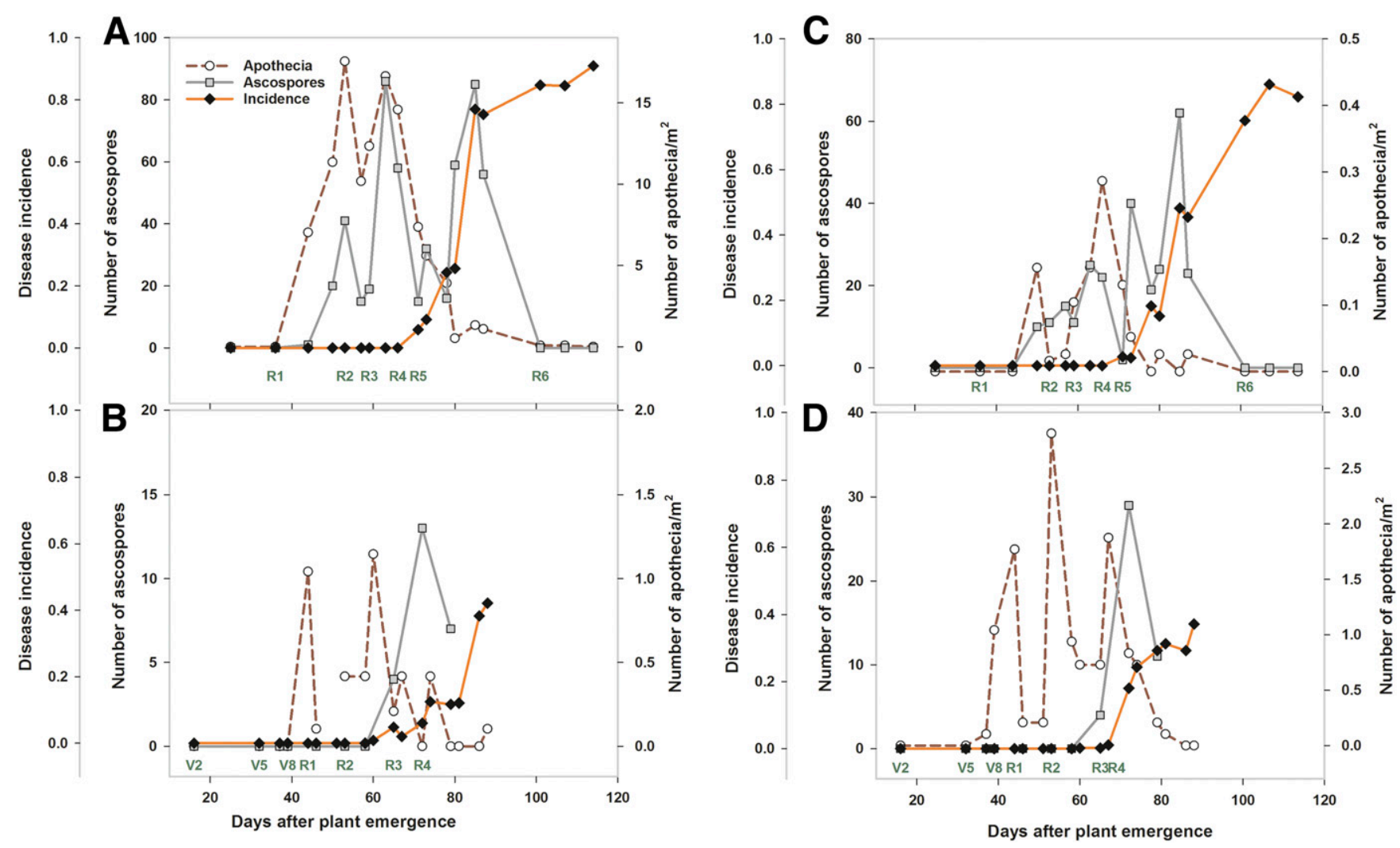

Fig. 1. Temporal dynamics of apothecia development, ascospore release, and incidence of Sclerotinia stem rot of soybean. Data were collected from an irrigated soybean field in Michigan with A, 0.36-m and C, 0.76-m row spacing in 2015 and B, 0.38-m and D, 0.76-m row spacing in 2016. Observations were typically conducted beginning before soybean flowering (V2, vegetative soybean growth stage) and continuing until the end of the flowering period (R1 to R3 soybean growth stage) or until soybean maturity (R6 soybean growth stage). 
Apothecia monitoring. In 2015, apothecia counts were taken twice weekly in eight $0.76-\mathrm{m}$ squares placed randomly throughout the plot so that the middle of each square was aligned with a row. Scouting was conducted in each trial for 12 weeks from 36 to 125 days after planting, beginning before the $\mathrm{R} 1$ growth stage and continuing through the R6 growth stage.

In 2016, apothecia counts were taken twice weekly in four 0.76by-0.76-m squares placed randomly throughout the plot so that the middle of each square was aligned with a row. The 0.76-m square was divided into 10 small rectangles (perpendicular lengthwise to the row) measuring 0.076 by $0.76 \mathrm{~m}$, and apothecia were counted in each small rectangle. The plots were scouted for 10 weeks from 28 to 100 days after seeding, beginning at the V2 (two trifoliate) soybean growth stage and continuing through the R4 soybean growth stage.

Ascospore monitoring and disease measurement. In both years, each plot was monitored for the presence of ascospores by means of bromophenol blue semiselective medium Petri plate traps (Foster et al. 2011; Steadman et al. 1994). The 90-mm Petri plate traps, which contained potato dextrose agar amended with $75 \%$ pentachloronitrobenzene at $25 \mathrm{mg} /$ liter, penicillin $\mathrm{G}$ (potassium salt) at $150 \mathrm{mg} / \mathrm{liter}$,

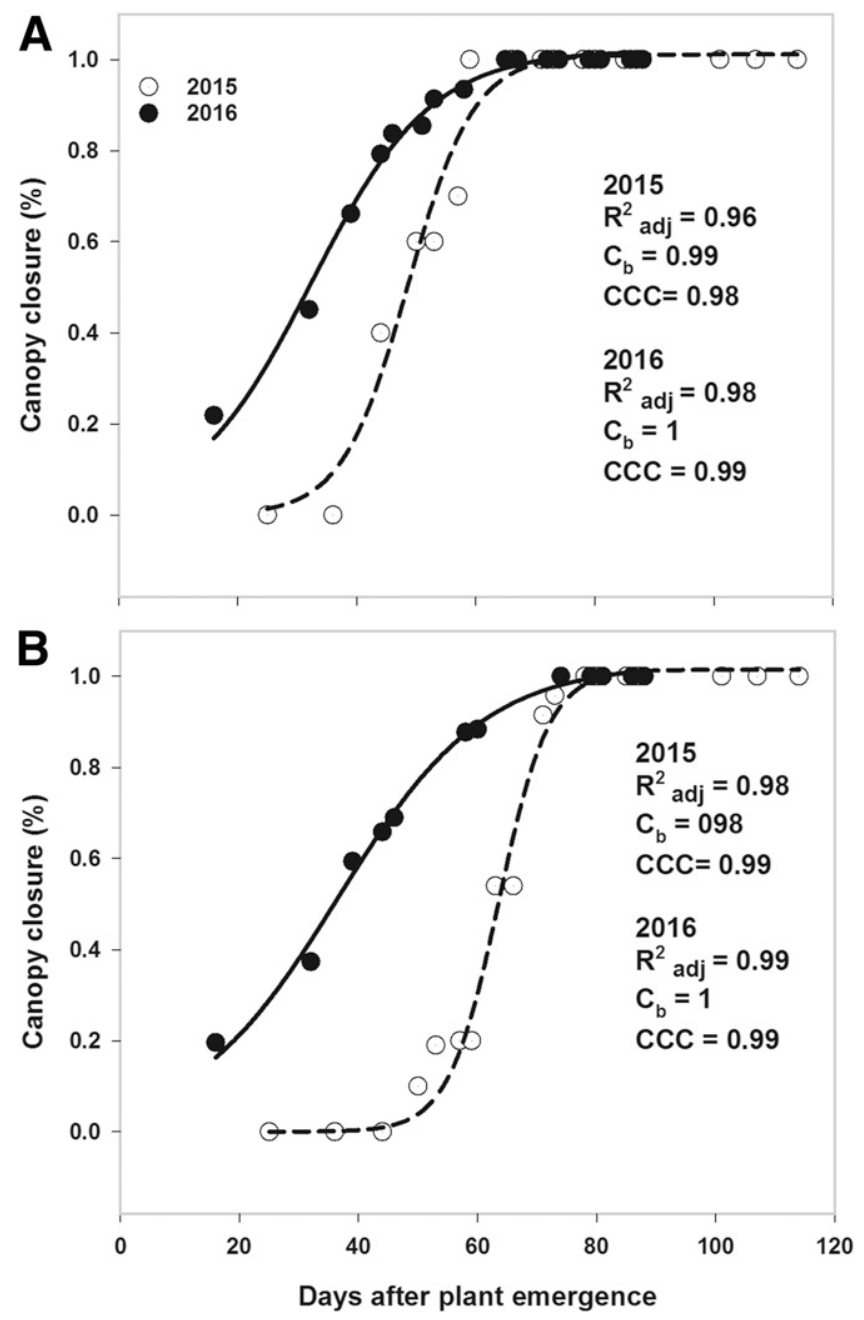

Fig. 2. Relationship between soybean canopy closure and the number of days after plant emergence under irrigated field conditions in Michigan with $\mathbf{A}$, narrow rowspacing $(0.36$ and $0.38 \mathrm{~m})$ in 2015 and 2016, respectively, and B, 0.76-m row spacing in both 2015 and 2016. Canopy closure was then calculated for each sampling day as follows: Canopy closure $=1-$ (daily measured distance/row spacing distance). For example, row spacing distance was 0.76 and $0.38 \mathrm{~m}$ for the $0.76-$ and $0.38-\mathrm{m}$ row-spacing trials, respectively. A three-parameter sigmoidal model was fitted to the scatter plot (see main text for equation description), and the concordance correlation coefficient (CCC), a generalized bias parameter $\left(\mathrm{C}_{\mathrm{b}}\right)$, and the adjusted coefficient of determination $\left(R_{\mathrm{adj}}^{2}\right)$ were used as measures of model appropriateness and goodness of fit. streptomycin sulfate at $150 \mathrm{mg} / \mathrm{liter}$, and bromophenol blue indicator at $50 \mathrm{mg} /$ liter, were placed beneath the soybean canopy at a $45^{\circ}$ angle, facing upwind, and were exposed for 1 to $3 \mathrm{~h}$ between 09:00 and 14:00 h (Foster et al. 2011). The Petri plate traps were subsequently incubated at room temperature $\left(21\right.$ to $\left.24^{\circ} \mathrm{C}\right)$ for 2 to 3 days, then evaluated for the presence of $S$. sclerotiorum CFU. The CFU were distinguishable by the characteristic yellow halo surrounding the small, circular, translucent white colonies. Colonies were best visualized using backlighting; or, on heavily infested plates, a dissecting microscope was used. Discrete CFU were considered to result from a single ascospore, and S. sclerotiorum detection was confirmed by the subsequent formation of characteristic sclerotia after representative colonies were subcultured (Willbur et al. 2018). The disease incidence was calculated in each sampling day by counting all plants with signs of SSR and dividing by total plant count.

Apothecia development and shade factor. To study the impact of light on apothecia germination, six shade boxes measuring 0.76 by $0.99 \mathrm{~m}$ were constructed in 2016. Each shade box (AgFabric Sunblock Shade Cloth; Wellco Industries Inc.) was divided into three sections (I, II, and III)) measuring 0.76 by $0.33 \mathrm{~m}$, and each section had a shade factor (percentage of light blocked) of 0, 30, 50, 70, 90, or $100 \%$, so that each shade factor was repeated three times (Supplementary Table S1). The shade boxes were randomly placed in different areas of the field that were not planted with soybean. Apothecia counts were taken twice weekly in each section of each shade box. Only the center of each section $(0.23$ by $0.66 \mathrm{~m})$ was scouted for apothecia.

Measurement of environmental variables. In 2015, weather data for May to Sept were obtained from the Michigan State University weather station in Montcalm (https://mawn.geo.msu.edu/station. asp?id=ent). Variables collected included the average air temperature, relative humidity, and soil temperature.

In 2016, in-field weather stations were placed in each row-spacing trial from May to September. Weather variables were monitored using a variety of sensors connected to a data logger which measured air temperature and relative humidity $2 \mathrm{~m}$ above the soil surface (WatchDog model 1450 Micro Station; Spectrum Technologies). Precipitation was monitored $1.5 \mathrm{~m}$ above the ground (tipping bucket gauge, model 3554WD1; Spectrum Technologies). Soil temperature, moisture, and electrical conductivity were monitored with a probe buried at $0.06 \mathrm{~m}$ into the soybean root zone (WaterScout SMEC 300, model 6470-6; Spectrum Technologies). Measurements were taken every $30 \mathrm{~min}$ and averaged to calculate the daily value of each weather variable.

Data analysis. All statistical tests were performed in R software, version 3.3.1 (https://www.r-project.org/), as described below.

Dynamics of apothecia production, ascospore release, canopy closure, and SSR development. Graphical representations were prepared to show the daily number of apothecia per square meter, number of ascospores per 9-cm-diameter Petri plate, and disease incidence as a function of the number of days after plant emergence in 2015 and 2016. A scatter plot representing the relationship between the percentage of canopy closure as function of days after plant emergence in 2015 and 2016 was prepared. To compare canopy closure between row-spacing amounts and years, a three-parameter sigmoidal model was fitted to the scatter plot, as follows:

$$
y=\frac{a}{1+e^{-\left(\frac{x-x_{0}}{b}\right)}}
$$

where $y$ is canopy closure, $a$ is the asymptote, $x_{0}$ is the day after plant emergence where $50 \%$ of the canopy is closed, and $b$ is the width of the exponential phase of the curve (Fall et al. 2015). The concordance correlation coefficient, a generalized bias parameter $\left(\mathrm{C}_{\mathrm{b}}\right)$, and the adjusted coefficient of determination were used as measures of model appropriateness and goodness of fit (Madden et al. 2007).

Apothecia production and environmental variables. Correlations among the number of apothecia, the number of ascospores, canopy closure, and selected weather variables (soil temperature, air temperature, and relative humidity) were analyzed using a Spearman rank correlation matrix in $\mathrm{R}$ software (Hmisc package 4.0-3). A scatter 
plot showing the number of apothecia as a function of the soil temperature was prepared, and a three-parameter Gaussian model was fitted to the scatter plot as follows:

$$
y=a * \exp \left(-0.5\left(\frac{x-x_{0}}{b}\right)^{2}\right)
$$

where $y$ is the number of apothecia, $a$ is the height of the curve's peak, $x_{0}$ is the x-axis coordinate at the curve's peak, and $b$ is the width of the curve's bell. The concordance correlation coefficient, $\mathrm{a}_{\mathrm{b}}$, and the adjusted coefficient of determination were used as measures of model appropriateness and goodness of fit (Madden et al. 2007). The numbers of apothecia for each shade factor (percentage of light blocked) were compared, and Kruskal-Wallis one-way analysis of variance on ranks was performed.

Spatiotemporal distribution of apothecia. A graphic representing the number of apothecia as function of the distance of the sampling points from the soybean row and the number of days after plant emergence was generated. To compare apothecia distribution and canopy closure, a graphical representation of canopy closure as function of the number of days after plant emergence was added to the previous graph, and a three-parameter sigmoidal model was fitted to the data (see equation 2). To test the spatial dependence of apothecia distribution, a spatial regression model (lag model) was compared with the ordinary least-squares (OLS) model. Number of apothecia was considered to be the dependent variable, and canopy closure and distance of the sampling points from the row were considered to be independent variables. The spatial weight matrix was based on distance $d$, which was the distance between the centroids of the small rectangles measuring 0.076 by $0.76 \mathrm{~m}$, where the apothecia counts were taken (as described above). Observations (apothecia counts) that were taken in the same small rectangle were considered to be neighbors, and the distance band was $0.076 \mathrm{~m}$. Spatial dependence tests (Moran's I tests) were calculated to determine whether there was a spatial

Table 1. Estimated parameters for three-parameter models describing the relationship between canopy closure and the number of days after plant emergence, the relationship between the number of apothecia per square meter and soil temperature, and the relationship between the number of apothecia per square meter and canopy closure ${ }^{\mathrm{a}}$

\begin{tabular}{|c|c|c|c|c|c|c|c|}
\hline \multirow[b]{2}{*}{ Row spacing, model } & \multirow[b]{2}{*}{ Parameter $^{\mathbf{b}}$} & \multicolumn{3}{|c|}{2015} & \multicolumn{3}{|c|}{2016} \\
\hline & & Estimate & SE & $P$ value & Estimate & SE & $P$ value \\
\hline \multicolumn{8}{|l|}{$0.36 \mathrm{~m}(0.38 \mathrm{~m})^{\mathrm{c}}$} \\
\hline \multirow{3}{*}{ Sigmoidal } & $a$ & 1.0000 & 0.0228 & $<0.0001$ & 1.000 & 0.0110 & $<0.0001$ \\
\hline & $b$ & 5.6924 & 0.8846 & $<0.0001$ & 10.2486 & 0.6458 & $<0.0001$ \\
\hline & $x_{0}$ & 48.6577 & 0.9274 & $<0.0001$ & 32.2711 & 0.6639 & $<0.0001$ \\
\hline \multirow[t]{3}{*}{ Gaussian } & $a$ & 18.4235 & 2.0825 & $<0.0001$ & 1.0691 & 0.1315 & $<0.0001$ \\
\hline & $b$ & 1.0594 & 0.1474 & $<0.0001$ & 0.4312 & 0.0471 & $<0.0001$ \\
\hline & $x_{0}$ & 23.5245 & 0.1478 & $<0.0001$ & 21.5358 & 0.0681 & $<0.0001$ \\
\hline \multirow[t]{3}{*}{ Gaussian } & $a$ & 13.2320 & 2.8133 & 0.0003 & 0.5942 & 0.1703 & 0.0045 \\
\hline & $b$ & 0.2371 & 0.0645 & 0.0025 & 0.1049 & 0.0319 & 0.0064 \\
\hline & $x_{0}$ & 0.6396 & 0.0806 & $<0.0001$ & 0.8183 & 0.0430 & $<0.0001$ \\
\hline \multicolumn{8}{|l|}{$0.76 \mathrm{~m}$} \\
\hline \multirow[t]{3}{*}{ Sigmoidal } & $a$ & 1.0000 & 0.0217 & $<0.0001$ & 1.000 & 0.0150 & $<0.0001$ \\
\hline & $b$ & 4.5282 & 0.4925 & $<0.0001$ & 12.6107 & 0.8380 & $<0.0001$ \\
\hline & $x_{0}$ & 63.4994 & 0.5803 & $<0.0001$ & 36.7326 & 0.7107 & $<0.0001$ \\
\hline \multirow[t]{3}{*}{ Gaussian } & $a$ & 0.2577 & 0.0427 & $<0.0001$ & 1.7764 & 0.3999 & 0.0008 \\
\hline & $b$ & 0.3946 & 0.0771 & 0.0002 & 0.7163 & 0.1938 & 0.0031 \\
\hline & $x_{0}$ & 22.8395 & 0.0999 & $<0.0001$ & 22.7354 & 0.1728 & $<0.0001$ \\
\hline \multirow[t]{3}{*}{ Gaussian } & $a$ & 0.2282 & 0.0279 & $<0.0001$ & 2.9584 & 0.7761 & 0.0041 \\
\hline & $b$ & 0.2076 & 0.0204 & $<0.0001$ & 0.0957 & 0.0171 & 0.0003 \\
\hline & $x_{0}$ & 0.5672 & 0.0365 & $<0.0001$ & 0.7934 & 0.0131 & $<0.0001$ \\
\hline
\end{tabular}

a $\mathrm{SE}=$ standard error. Significance code: $P<0.05$.

$\mathrm{b}$ In the three-parameter sigmoidal model, $a$ is the asymptote, $b$ is the width of the exponential phase of the curve, and $x_{0}$ is the day after plant emergence when $50 \%$ of the canopy is closed. In the three-parameter Gaussian model, $a$ the height of the curve's peak, $b$ is the width of the exponential phase of the curve, and $x_{0}$ is the $\mathrm{X}$-axis coordinate at the curve's peak. The $x_{0}$ is an estimate of the value of canopy closure at the peak position (highest number of apothecia).

${ }^{\mathrm{c}}$ Row spacing was $0.36 \mathrm{~m}$ in 2015 and $0.38 \mathrm{~m}$ in 2016.

Table 2. Spearman correlation matrix for number of apothecia, number of ascospores, average daily soil temperature, average daily air temperature, relative humidity, and canopy closure in $2015^{\text {a }}$

\begin{tabular}{|c|c|c|c|c|c|c|}
\hline Row spacing, variables & 1 & 2 & 3 & 4 & 5 & 6 \\
\hline \multicolumn{7}{|l|}{$0.36 \mathrm{~m}$} \\
\hline 1. Number of apothecia & 1 & $0.60 * *(0.0079)$ & $0.73 * *(0.0015)$ & $0.50 *(0.0365)$ & $-0.32(0.1959)$ & $0.06(0.8154)$ \\
\hline 2. Number of ascospores & $\ldots$ & 1 & $0.21(0.4336)$ & $-0.08(0.7388)$ & $0.28(0.2519)$ & $0.37(0.1290)$ \\
\hline 3. Soil temperature & $\ldots$ & $\ldots$ & 1 & $0.74 * *(0.0012)$ & $-0.42(0.1058)$ & $-0.24(0.3793)$ \\
\hline 4. Air temperature & $\ldots$ & $\ldots$ & $\ldots$ & 1 & $-0.57 *(0.0126)$ & $-0.16(0.5323)$ \\
\hline 5. Relative humidity & $\ldots$ & $\ldots$ & $\ldots$ & $\ldots$ & 1 & $0.30(0.2199)$ \\
\hline 6. Canopy closure & $\ldots$ & $\ldots$ & $\ldots$ & $\ldots$ & $\ldots$ & 1 \\
\hline \multicolumn{7}{|l|}{$0.76 \mathrm{~m}$} \\
\hline 1. Number of apothecia & 1 & $0.51 *(0.0324)$ & $0.66 * *(0.0059)$ & $0.34(0.1623)$ & $-0.10(0.6912)$ & $-0.10(0.6911)$ \\
\hline 2. Number of ascospores & $\ldots$ & 1 & $0.12(0.6574)$ & $0.00(0.9967)$ & $0.33(0.1764)$ & $0.34(0.1727)$ \\
\hline 3. Soil temperature & $\ldots$ & $\ldots$ & 1 & $0.74 * *(0.0012)$ & $-0.42(0.1258)$ & $-0.65 * *(0.0062)$ \\
\hline 4. Air temperature & $\ldots$ & $\ldots$ & $\ldots$ & 1 & $-0.57 *(0.0126)$ & $-0.35(0.1491)$ \\
\hline 5. Relative humidity & $\ldots$ & $\ldots$ & $\ldots$ & $\ldots$ & 1 & $0.50 *(0.0348)$ \\
\hline 6. Canopy closure & $\ldots$ & $\ldots$ & $\ldots$ & $\ldots$ & $\ldots$ & 1 \\
\hline
\end{tabular}

a This study on Sclerotinia stem rot was done in a field at Michigan State University's Montcalm Research Center in Montcalm, MI. Asterisks: ***, **, and * indicate $P<0.001,0.01$, and 0.05 , respectively. Numbers in parentheses are the exact $P$ values. 
dependence. To describe the relationship between the number of apothecia per square meter and canopy closure, a scatter plot showing the number of apothecia as function of canopy closure was prepared, and a three-parameter Gaussian model was fitted to the scatter plot. The concordance correlation coefficient, $\mathrm{a} \mathrm{C}_{\mathrm{b}}$, and the adjusted coefficient of determination were used as measures of model appropriateness and goodness of fit (Madden et al. 2007).

\section{Results}

Dynamics of apothecia production, ascospore release, canopy closure, and SSR development. In 2015, the maximum numbers of apothecia were 16.64 and 0.29 apothecia $/ \mathrm{m}^{2}$ in the $0.36-$ and $0.76-\mathrm{m}$ row-spacing trials, respectively (Fig. 1A and C). The maximum number of apothecia was 50 times higher with the $0.36-\mathrm{m}$ row spacing than with the 0.76-m row spacing. Apothecia production was observed between R1 and R5 soybean growth stages and between the $\mathrm{R} 2$ and R5 soybean growth stages in the 0.36- and 0.76-m rowspacing trials, respectively (Fig. 1A and C). The maximum numbers of ascospores were 86 and $62 \mathrm{CFU}$ per 9-cm-diameter Petri plate in the $0.36-$ and $0.76-\mathrm{m}$ row-spacing trials, respectively. In the $0.36-\mathrm{m}$ row-spacing trial, disease incidence reached 75 and $91 \%$ at 88 and 114 days after plant emergence, respectively. In the $0.76-\mathrm{m}$ rowspacing trial, disease incidence reached 45 and $82 \%$ at 88 and 114 days after plant emergence, respectively (Fig. 1). With the $0.36-\mathrm{m}$ row spacing, the values of $x_{0}$ and $b$ for canopy closure were 48.66 and 5.69, respectively (Fig. 2A; Table 1), whereas, with the $0.76-\mathrm{m}$ row spacing, the values of $x_{0}$ and $b$ were 63.49 and 4.53 , respectively (Fig. 2B; Table 1).

In 2016, the maximum numbers of apothecia were 1.15 and 2.81 apothecia $/ \mathrm{m}^{2}$ in the 0.38 - and $0.76-\mathrm{m}$ row-spacing trials, respectively
(Fig. 1B and D). The maximum number of apothecia was 2.5 times higher in the $0.76-\mathrm{m}$ row-spacing trial than in the $0.38-\mathrm{m}$ rowspacing trial. Apothecia production was observed between the V8 (eight trifoliate) soybean growth stage and R4 soybean growth stage in both row-spacing trials (Fig. 1B and D). The maximum numbers of ascospores were 13 and 29 CFU per 9-cm-diameter Petri plate in the 0.38 - and $0.76-\mathrm{m}$ row-spacing trials, respectively. At 88 days after plant emergence, disease incidence reached 42 and $37 \%$ in the 0.38- and 0.76-m row-spacing trials, respectively (Fig. 1). With the $0.36-\mathrm{m}$ row spacing, the values of $x_{0}$ and $b$ were 32.27 and 10.24 , respectively (Fig. 2A; Table 1), whereas, with the 0.76-m row spacing, the values of $x_{0}$ and $b$ were 36.73 and 12.61, respectively (Fig. 2B; Table 1$)$. In the narrow row-spacing trials ( 0.36 and $0.38 \mathrm{~m})$, canopy closure reached 50\% 17 days earlier in 2016 than in 2015. In the 0.76$\mathrm{m}$ row-spacing trials, canopy closure reached 50\% 27 days earlier in 2016 than in 2015 (Fig. 2; equation 2). In the narrow row-spacing trials, the speed with which the canopy closed was two times faster in 2015 than in 2016 (Fig. 2; equation 2). With the 0.76-m row spacing, the speed with which the canopy closed was three times faster in 2015 than in 2016. During the early part of the season (the first 50 days after plant emergence), the speed of canopy closure was higher in 2016 than in 2015 in both row-spacing trials (Fig. 2; equation 2). In both rowspacing trials, apothecia were observed earlier in 2016 (before the $\mathrm{R} 1$ growth stage) than in 2015 (between R1 and R2).

Apothecia and ascospore production and environmental variables. In 2015, the number of apothecia was significantly and positively correlated with the number of ascospores and soil temperature in both row-spacing trials. Air temperature was positively correlated with the number of apothecia in the $0.36-\mathrm{m}$ row-spacing trial (Table 2). In 2016 , the number of apothecia was positively and significantly

Table 3. Spearman correlation matrix for number of apothecia, average daily soil temperature, average daily air temperature, relative humidity, and canopy closure in $2016^{\mathrm{a}}$

\begin{tabular}{|c|c|c|c|c|c|}
\hline Row spacing, variables & 1 & 2 & 3 & 4 & 5 \\
\hline \multicolumn{6}{|l|}{$0.38 \mathrm{~m}$} \\
\hline 1. Number of apothecia & 1 & $0.04(0.8818)$ & $0.56 *(0.0163)$ & $0.48 *(0.0435)$ & $0.18(0.4911)$ \\
\hline 2. Soil temperature & $\ldots$ & 1 & $0.42(0.0827)$ & $-0.03(0.9126)$ & $-0.55^{*}(0.0232)$ \\
\hline 3. Air temperature & $\ldots$ & $\ldots$ & 1 & $0.56 *(0.0156)$ & $0.12(0.6334)$ \\
\hline 4. Relative humidity & $\ldots$ & $\ldots$ & $\ldots$ & 1 & $0.46(0.0604)$ \\
\hline 5. Canopy closure & $\ldots$ & $\ldots$ & $\ldots$ & $\ldots$ & 1 \\
\hline \multicolumn{6}{|l|}{$0.76 \mathrm{~m}$} \\
\hline 1. Number of apothecia & 1 & $0.44 *(0.0459)$ & $0.60 * *(0.0086)$ & $0.27(0.2767)$ & $-0.11(0.7174)$ \\
\hline 2. Soil temperature & $\ldots$ & 1 & $0.40(0.1006)$ & $-0.17(0.4993)$ & $-0.48(0.0983)$ \\
\hline 3. Air temperature & $\ldots$ & $\ldots$ & 1 & $0.35(0.1521)$ & $0.20(0.5104)$ \\
\hline 4. Relative humidity & $\ldots$ & $\ldots$ & $\ldots$ & 1 & $0.71 * *(0.0065)$ \\
\hline 5. Canopy closure & $\ldots$ & $\ldots$ & $\ldots$ & $\ldots$ & 1 \\
\hline
\end{tabular}

${ }^{\text {a }}$ This study on Sclerotinia stem rot was done in a field at Michigan State University's Montcalm Research Center in Montcalm, MI. Asterisks: ***, **, and * indicate $P<0.001,0.01$, and 0.05 , respectively. Numbers in parentheses are the exact $P$ values.

Table 4. Spatial and ordinary least-squares (OLS) regression analysis of the effect of canopy closure and the distance from the soybean row on the number of Sclerotinia sclerotiorum apothecia ${ }^{\mathrm{a}}$

\begin{tabular}{|c|c|c|c|c|c|c|c|}
\hline \multirow[b]{2}{*}{ Row spacing, estimate } & \multicolumn{4}{|c|}{ Regression model } & \multicolumn{3}{|c|}{ Moran's I } \\
\hline & OLS & AIC & Spatial lag & AIC & Statistic & Variance & $P$ value \\
\hline \multicolumn{8}{|l|}{$0.38 \mathrm{~m}$} \\
\hline Intercept & 2.86 & 243.75 & 1.91 & 244.86 & -0.38 & 0.02 & 0.64 \\
\hline Canopy closure & 1.38 & $\ldots$ & 0.00 & $\ldots$ & $\ldots$ & $\ldots$ & $\ldots$ \\
\hline Distance from row $(\mathrm{m})$ & $-11.76^{*}$ & $\ldots$ & $-11.08 * *$ & $\ldots$ & $\ldots$ & $\ldots$ & $\ldots$ \\
\hline Rho & $\ldots$ & $\ldots$ & -0.43 & $\ldots$ & $\ldots$ & $\ldots$ & $\ldots$ \\
\hline \multicolumn{8}{|l|}{$0.76 \mathrm{~m}$} \\
\hline Intercept & $1.32 *$ & 447.57 & $1.47^{*}$ & 449.55 & 1.97 & 0.00 & $0.02 *$ \\
\hline Canopy closure & $3.40 *$ & $\ldots$ & $3.4 * *$ & $\ldots$ & $\ldots$ & $\ldots$ & $\ldots$ \\
\hline Distance from row (m) & $-5.81^{*}$ & $\ldots$ & $-6.03^{*}$ & $\ldots$ & $\ldots$ & $\ldots$ & $\ldots$ \\
\hline Rho & $\ldots$ & $\ldots$ & $0.45^{*}$ & $\cdots$ & $\ldots$ & $\ldots$ & $\ldots$ \\
\hline
\end{tabular}

${ }^{a}$ This study on Sclerotinia stem rot was done in a field at Michigan State University's Montcalm Research Center in Montcalm, MI. AIC $=$ Akaike information criterion, for measuring the relative quality of the models. Asterisks: $* * *, * *$, and $*$ indicate $P<0.001,0.01$, and 0.05 , respectively. Numbers in parentheses are the exact $P$ values. 
correlated with air temperature and relative humidity in the $0.38-\mathrm{m}$ row-spacing trial whereas, in the $0.76-\mathrm{m}$ row-spacing trial, the number of apothecia was positively and significantly correlated with soil temperature and air temperature (Table 3 ). In summary, there were significant positive correlations between the number of apothecia and the soil temperature in 2015 and 2016 in both row-spacing trials, except the $0.38-\mathrm{m}$ row spacing in 2016; air temperature was the second important variable in relation to apothecia production (Tables 3 and 4). There was an exponential (three-parameter Gaussian) relationship between the number of apothecia and the soil temperature for both row-spacing trials and both years (Fig. 3; Table 1). Apothecia were observed when the soil temperature was between 20 and $25^{\circ} \mathrm{C}$. The peak number of apothecia occurred when the soil temperature was between 21.5 and $23.5^{\circ} \mathrm{C}$ and apothecia production did not occur at soil temperatures above $25^{\circ} \mathrm{C}$ (Fig. 3; Table 1).

Spatiotemporal distribution of apothecia and shade factor influence on apothecia production. In 2015, apothecia were first observed when canopy closure reached $40 \%$ (7.03 apothecia $/ \mathrm{m}^{2}$, 44 days after plant emergence) in the $0.36-\mathrm{m}$ row-spacing trial (Fig. 4A) whereas, in the $0.76-\mathrm{m}$ row-spacing trial, apothecia were first observed when canopy closure reached $20 \%$ (0.03 apothecium $/ \mathrm{m}^{2}, 57$ days after plant emergence) (Fig. 4C). The peak number of apothecia with the $0.36-\mathrm{m}$ row spacing was observed when the canopy was $65 \%$ closed (63 days after plant emergence) (Fig. 4A; Table 1) whereas, with the $0.76-\mathrm{m}$ row spacing, the peak number of apothecia was reached when the canopy was 56\% closed (66 days after plant emergence) (Fig. 4C; Table 1). Overall, to reach 0.3 apothecium $/ \mathrm{m}^{2}$, at least $40 \%$ of the canopy should be closed (Fig. 4C; Table 1).
In 2016, apothecia were first observed when canopy closure reached $79 \%$ (1.04 apothecia/ $\mathrm{m}^{2}, 44$ days after plant emergence) in the $0.38-\mathrm{m}$ row-spacing trial (Figs. 4B and 5A) whereas, in the 0.76-m row-spacing trial, apothecia were first observed when canopy closure reached 59\% (1.04 apothecia $/ \mathrm{m}^{2}, 39$ days after plant emergence) (Figs. 4D and 5B). The peak number of apothecia with the $0.38-\mathrm{m}$ row spacing was reached after the canopy was $81 \%$ closed (60 days after plant emergence) (Fig. 4B; Table 1) whereas, with the $0.76-\mathrm{m}$ row spacing, the peak number of apothecia was reached after the canopy was $79 \%$ closed (58 days after plant emergence) (Fig. 4B; Table 1). In both row-spacing trials, a three-parameter Gaussian model explained much of the relationship $(P<0.05)$ between canopy closure and the number of apothecia (Fig. 4; Table 1), with all estimated coefficients for the three-parameter Gaussian model being significant (Table 1). There was no apothecia production between rows (middle of the row) until the canopy was completely closed (Fig. 5). In the $0.38-\mathrm{m}$ row-spacing trial, the OLS model was statistically significant $(P=0.024)$ and the spatial lag model was not significant $(P=0.215)$. Canopy closure positively influenced the number of apothecia, whereas the distance from the row negatively influenced it. The impact of the distance of sampling from the row on the number of apothecia was eight times higher than the impact of canopy closure. According to Moran's I test, there was no spatial dependence in apothecia distribution (Table 4). In the 0.76$\mathrm{m}$ row-spacing trial, both models (OLS and spatial lag) were statistically significant $(P=0.041$ and 0.040 , respectively). Canopy closure positively influenced the number of apothecia, whereas the distance from the row negatively influenced it. The impact of the distance from the row on the number of apothecia was two times higher
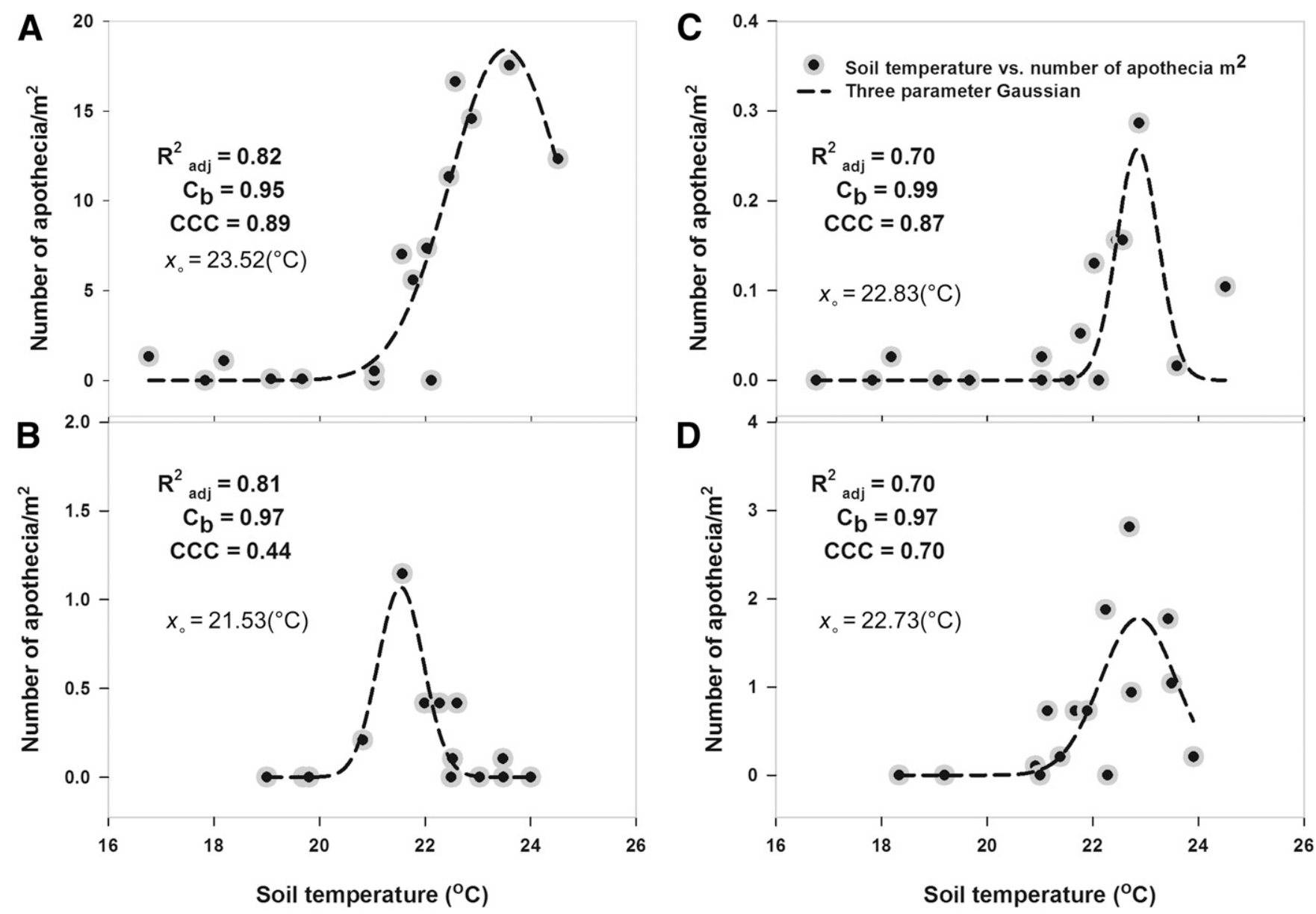

Fig. 3. Relationship between the daily number of apothecia per square meter and the daily average soil temperature with $\mathbf{A}, 0.36-\mathrm{m}$ and $\mathbf{C}, 0.76-\mathrm{m}$ row spacing in 2015 and with $\mathbf{B}$, 0.38-m and D, 0.76-m row spacing in 2016. A three-parameter Gaussian model was fitted to the scatter plot (see main text for equation description), and the concordance correlation coefficient $(\mathrm{CCC})$, a generalized bias parameter $\left(\mathrm{C}_{\mathrm{b}}\right)$, and the adjusted coefficient of determination $\left(R_{\mathrm{adj}}^{2}\right)$ were used as measures of model appropriateness and goodness of fit. The $x_{0}$ is an estimate of the value of the soil temperature at the peak position (highest number of apothecia per square meter). 
than the impact of canopy closure. According to Moran's I test, there was a spatial dependence in apothecia distribution (Table 4). The numbers of apothecia for each shade factor were significantly different $(P=0.031)$. In $91 \%$ of the cases, the presence of apothecia was observed when the shade factor (percentage of light blocked) was $70 \%$ (41 apothecia out of 45 total apothecia), and no apothecia germinated when the shade factor was 0,30 , or $100 \%$.

\section{Discussion}

Complete control of SSR of soybean in the north-central region of the United States has not been accomplished through fungicide applications, partly because of the difficulty of determining optimal application timing. Recently, apothecia production models (Willbur et al. 2018) were developed to determine the best fungicide timing. The models are weather driven and incorporate 30-day moving averages of maximum air temperature, relative humidity, and wind speed. However, as highlighted by Foster et al. (2011) and Willbur et al. (2018), the initiation parameters of such apothecia production models require information on canopy closure. To the best of our knowledge, this study provides the first quantitative description of the relationship between $S$. sclerotiorum apothecia production and canopy closure in soybean.

Canopy closure significantly explained the variability in the number of apothecia regardless of the row spacing. Canopy closure reached 50\% earlier in 2016 than in 2015, and the speed of canopy closure during the first 50 days after plant emergence was faster in 2016 than in 2015 . Consequently, apothecia production occurred earlier in 2016 (before the soybean flowering period) than in 2015 (during the soybean flowering period). These results differ from those of Boland and Hall (1988a), who found in their 2-year study that soybean reached at least the R1 growth stage before apothecia were observed. Regardless of row spacing, our results suggest that, in order for the apothecia count to reach 0.3 apothecium $/ \mathrm{m}^{2}$, which is the economic action threshold for implementing chemical control (Pan et al. 2001), at least $40 \%$ of the canopy should be closed. The peak number of apothecia was observed when canopy closure reached at least $50 \%$. Apothecia production was followed by a continuous or intermittent discharge of ascospores in all trials except the 0.76-m row-spacing trial in 2015, where ascospores were observed before apothecia. The proximity between the two row-spacing trials suggests that some ascospores may have blown from the $0.36-\mathrm{m}$ rowspacing trial or surrounding trials into the $0.76-\mathrm{m}$ row-spacing trial.

On a yearly basis, the number of apothecia was higher in 2015 than in 2016, and the maximum number of apothecia was 50 times higher with the $0.36-\mathrm{m}$ row spacing than with the $0.76-\mathrm{m}$ row spacing in 2015 but 2.5 times higher with the $0.76-\mathrm{m}$ row spacing than with the $0.38-\mathrm{m}$ row spacing in 2016 . In both row-spacing trials, there was no apothecia production between the rows (middle of the row) until the canopy was completely closed. Indeed, canopy closure positively influenced the number of apothecia even when the aggregate distribution of apothecia (Boland and Hall 1988b) was considered; hence, as the canopy was closing, more apothecia germinated. Also, the distance of the sampling points from the row negatively influenced the number of apothecia, and the impact of that distance was eight times higher than the impact of canopy closure. Indeed, the conditions for apothecia production are necessarily different at the
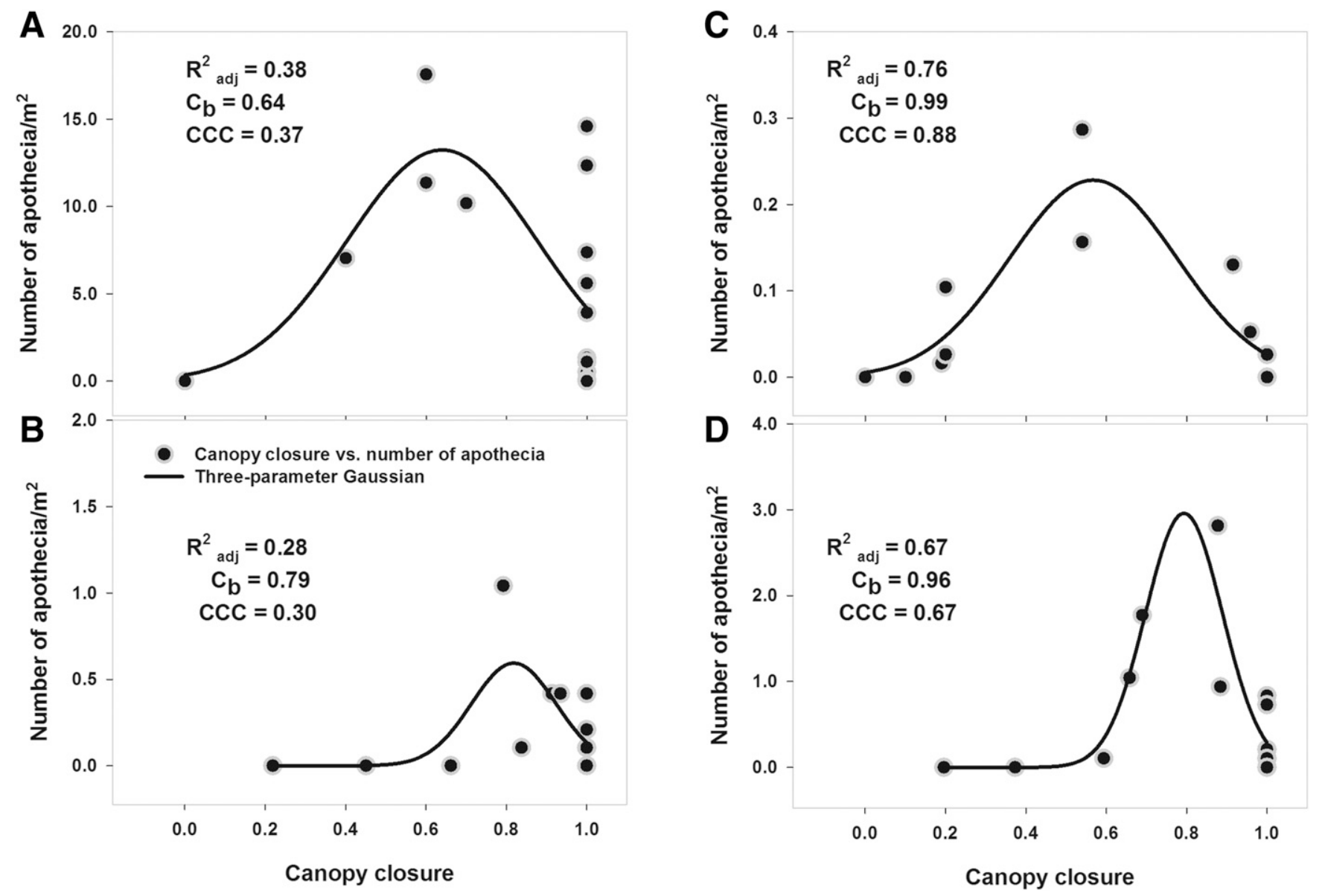

Fig. 4. Relationship between the daily number of apothecia per square meter and daily average canopy closure with A, 0.36-m and C, 0.76-m row spacing in 2015 and with B, 0.38 $\mathrm{m}$ and $\mathrm{D}, 0.76-\mathrm{m}$ row spacing in 2016. Canopy closure was then calculated for each sampling day as follows: Canopy closure $=1-$ (daily measured distance/row spacing distance). For example, row spacing distance was 0.76 and $0.38 \mathrm{~m}$ for the 0.76 - and $0.38-\mathrm{m}$ row-spacing trials, respectively. A three-parameter Gaussian model was fitted to the scatter plot (see main text for equation description), and the concordance correlation coefficient (CCC), a generalized bias parameter $\left(\mathrm{C}_{\mathrm{b}}\right)$, and the adjusted coefficient of determination $\left(R_{\mathrm{adj}}^{2}\right)$ were used as measures of model appropriateness and goodness of fit. 
sampling points in the row, where the effect of plant shade dilutes the spectrum and intensity of light reaching the soil. Compare these conditions to those for sampling points in the space between the rows, which is subjected to intense conditions (light and temperature). Our results in the shade factor trial (percentage of light blocked) suggest that, in $91 \%$ of the cases, the presence of apothecia was observed when the percentage of light blocked was $70 \%$, and no apothecia germinated in the absence of light or under full light exposure. According to Moran's I test, there was a spatial dependence in apothecia distribution only at the $0.76-\mathrm{m}$ row spacing; however, the spatial dependence did not significantly change the weight of canopy closure and distance of sampling points from the row in the regression models (OLS model versus spatial lag model). These results may explain why planting with wide row spacing rather than narrow row spacing was previously suggested as a successful management practice for SSR control in dry bean (Steadman et al. 1973). Previous studies related the development and severity of SSR in carrot and bean to the architectural attributes of the plant canopy (Blad et al. 1978; Kora et al. 2005). Blad et al. (1978) suggested that at least partial control of SSR can be achieved through planting cultivars with open canopy structures. Indeed, the microclimate conditions generated by canopy closure appeared to maintain an extended period of favorable conditions for apothecia germination, as reported in soybean (Boland and Hall 1988a) and bean (Boland and Hall 1987). The closure of the soybean canopy will necessarily and continuously affect the microclimate beneath the canopy.

Soil temperature and air temperature were the only tested weather variables that significantly affected the number of apothecia across years in both row-spacing trials. Numerous studies, in different locations, have suggested that particular soil temperatures are required for apothecia production (Dillard et al. 1995; Huang and Kozub 1991; Kohn 1979; Mila and Yang 2008; Phillips 1986; Ramsey 1925; Saito 1977; Sun and Yang 2000). In both row-spacing trials in our study, the relationship between the number of apothecia and soil temperature was significantly described by a three-parameter Gaussian model. Apothecia were observed when the soil temperature was between 20 and $25^{\circ} \mathrm{C}$, and the peak number of apothecia occurred when the average soil temperature at the $0.06-\mathrm{m}$ depth was between 21.5 and $23.5^{\circ} \mathrm{C}$. These ranges of temperatures are different from those described in previous studies, where favorable soil temperatures for the production of apothecia were mostly between 10 and $20^{\circ} \mathrm{C}$. However, all of those studies were done under artificial conditions with stable temperatures (i.e., growth chambers), and the results for specific soil temperature requirements differed among the studies (Dillard et al. 1995; Huang and Kozub 1991; Kohn 1979; Mila and Yang 2008; Phillips 1986; Ramsey 1925; Saito 1977; Sun and Yang 2000). Overall, apothecia production did not occur at soil temperatures above $25^{\circ} \mathrm{C}$. This result was similar to those of Hao et al. (2003), who reported that apothecia production was not observed at 25 and $30^{\circ} \mathrm{C}$. In our investigation, no significant relationship was observed between the number of apothecia and the other tested weather variables, except for air temperature in 2015 with the $0.36-\mathrm{m}$ row spacing and in 2016 with the $0.76-\mathrm{m}$ row spacing. Because the fields were irrigated over the course of this study, soil moisture was not tested. However, soil moisture was previously reported to be the most common limiting factor for apothecia production (Abawi and Grogan 1975; Grau 1989; Matheron and Porchas 2005; Sun and Yang 2000). It was also noted that, prior to the initiation of irrigation,

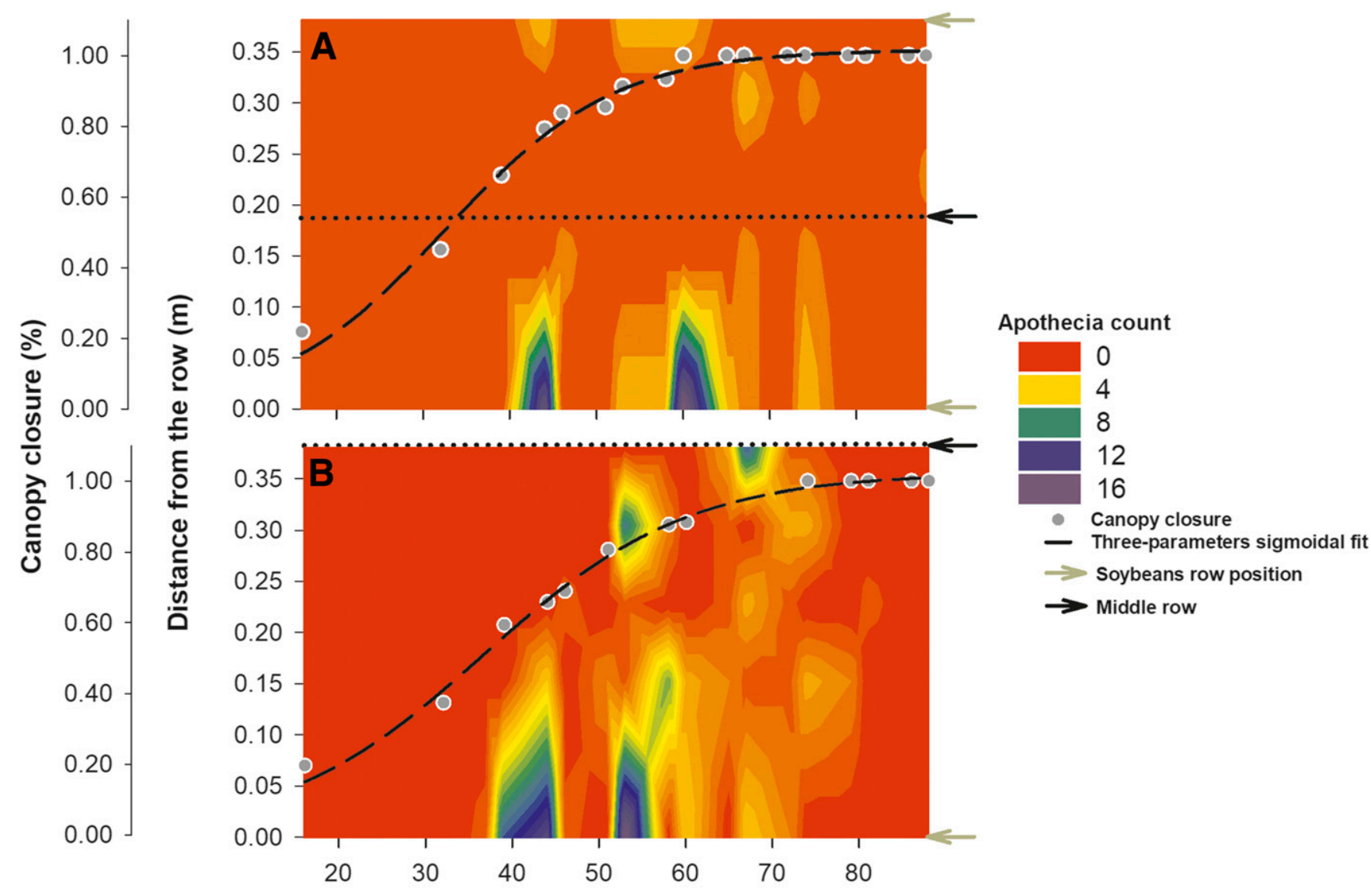

Days after plant emergence

Fig. 5. Spatiotemporal distribution of Sclerotinia sclerotiorum apothecia (color scale) as a function of the distance ( $y$-axis) of the sampling points from the row (indicated with dotted line and arrows), canopy closure (sigmoidal curves and secondary $y$-axis), and the number of days after plant emergence (x-axis) with $\mathbf{A}, 0.38-\mathrm{m}$ and B, 0.76-m row spacing. Data were collected from an irrigated soybean field in Michigan. Canopy closure was then calculated for each sampling day as follows: Canopy closure $=1-$ (daily measured distance/ row spacing distance). For example, row spacing distance was 0.76 and $0.38 \mathrm{~m}$ for the 0.76 - and $0.38-\mathrm{m}$ row-spacing trials, respectively. 
2015 was a wetter season, with $153 \mathrm{~mm}$ of rainfall recorded between 15 May and 1 July and $63 \mathrm{~mm}$ for the same period in 2016, which may also have affected apothecia development.

Integrated, multifaceted strategies offer the best chance for the successful management of SSR in soybean. Such approaches include implementation of better cultural practices, monitoring of SSR in each soybean field, crop rotation, irrigation management, and canopy management (Peltier et al. 2012). The present study examined the relationship between the closure of the soybean canopy, selected weather variables, and the number of apothecia. The results show that, under irrigated soybean field conditions, canopy closure and soil temperature significantly affected the spatiotemporal distribution of apothecia of $S$. sclerotiorum. The relationship between soybean canopy closure or soil temperature and the number of apothecia per square meter was significantly described by a three-parameter Gaussian model. In order for the apothecia count to reach 0.3 apothecium $/ \mathrm{m}^{2}$, which is the economic action threshold for implementing chemical control (Pan et al. 2001), at least $40 \%$ of the canopy should be closed, and apothecia production occurs when the soil temperature is between 20 and $25^{\circ} \mathrm{C}$. Canopy density influences apothecia production and, consequently, may partially explain the effect of the herbicide lactofen on SSR development (Dann et al. 1999; Huzar-Novakowiski et al. 2017). By causing phytotoxicity and distorting the shape of soybean leaves (Huzar-Novakowiski et al. 2017), herbicides open the canopy for a short time, thus delaying apothecia germination. Our study lays the groundwork for the future use of a canopy closure percentage of $40 \%$ and a soil temperature between 20 and $25^{\circ} \mathrm{C}$ as risk indicators for the production of apothecia, and for the integration of those indicators as initiation parameters into the recently developed apothecia production models.

\section{Acknowledgments}

We thank J. Bunner and Z. Sundin for their assistance with data collection.

\section{Literature Cited}

Abawi, G. S., and Grogan, R. G. 1975. Source of primary inoculum and effects of temperature and moisture on infection of beans by Whetzelinia sclerotiorum. Phytopathology 65:300-309.

Abawi, G. S., and Grogan, R. G. 1979. Epidemiology of diseases caused by Sclerotinia species. Phytopathology 69:899-903.

Allen, T. W., Bradley, C. A., Sisson, A. J., Byamukama, E., Chilvers, M. I., Coker, C. M., Collins, A. A., Damicone, J. P., et al. 2017. Soybean yield loss estimates due to diseases in United States and Ontario, Canada, from 2010 to 2014. Online publication. Plant Health Prog. https://doi.org/10.1094/PHP-RS-16-0066

Blad, B. L., Steadman, J. R., and Weiss, A. 1978. Canopy structure and irrigation influence white mold disease and microclimate of dry edible beans. Phytopathology 68:1431-1437.

Boland, G. J., and Hall, R. 1987. Epidemiology of white mold of white bean in Ontario. Can. J. Plant Pathol. 9:218-224.

Boland, G. J., and Hall, R. 1988a. Epidemiology of Sclerotinia stem rot of soybean in Ontario. Phytopathology 78:1241-1245.

Boland, G. J., and Hall, R. 1988b. Relationships between the spatial pattern and number of apothecia of Sclerotinia sclerotiorum and stem rot of soybean. Plant Pathol. 37:329-336.

Boland, G. J., and Hall, R. 1994. Index of plant hosts of Sclerotinia sclerotiorum. Can. J. Plant Pathol. 16:93-108.

Byrne, A., and Chilvers, M. 2014. Efficacy of foliar fungicides for white mold management of soybean in Michigan, 2014. Plant Dis. Manage. Rep. 9:FC055.

Chilvers, M., and Byrne, A. 2015. Efficacy of foliar fungicides for white mold management of soybean in Michigan, 2015. Plant Dis. Manage. Rep. 10: FC023.

Clarkson, J. P., Phelps, K., Whipps, J. M., Young, C. S., Smith, J. A., and Watling, M. 2004. Forecasting Sclerotinia disease on lettuce: Toward developing a prediction model for carpogenic germination of sclerotia. Phytopathology 94:268-279.

Dann, E. K., Diers, B. W., and Hammerschmidt, R. 1999. Suppression of Sclerotinia stem rot of soybean by lactofen herbicide treatment. Phytopathology 89:598-602.

Dillard, H. R., Ludwig, J. W., and Hunter, J. E. 1995. Conditioning sclerotia of Sclerotinia sclerotiorum for carpogenic germination. Plant Dis. 79:411-415.

Fall, M. L., Boyse, J. F., Wang, D., Willbur, J., Smith, D. L., and Chilvers, M. 2018. Case study of an epidemiological approach dissecting historical soybean Sclerotinia stem rot observations and identifying environmental predictors of epidemics and yield loss. Phytopathology 108:469-478.

Fall, M. L., Van der Heyden, H., Beaulieu, C., and Carisse, O. 2015. Bremia lactucae infection efficiency in lettuce is modulated by temperature and leaf wetness duration under Quebec field conditions. Plant Dis. 99:1010-1019.
Foster, A. J., Kora, C., McDonald, M. R., and Boland, G. J. 2011. Development and validation of a disease forecast model for Sclerotinia rot of carrot. Can. J. Plant Pathol. 33:187-201.

Grau, C. R. 1988. Sclerotinia stem rot of soybean. Pages 56-66 in: Soybean Diseases of the North Central Region. T. D. Wyllie and D. H. Scott, eds. American Phytopathological Society, St. Paul, MN.

Grau, C. R. 1989. Sclerotinia stem rot. Pages 47-48 in: Compendium of Soybean Diseases, 3rd ed. J. B. Sinclair and P. A. Backman, eds. American Phytopathological Society, St. Paul, MN.

Hao, J. J., Subbarao, K. V., and Duniway, J. M. 2003. Germination of Sclerotinia minor and $S$. sclerotiorum sclerotia under various soil moisture and temperature combinations. Phytopathology 93:443-450.

Huang, H. C., and Kozub, G. C. 1991. Temperature requirements for carpogenic germination of sclerotia of Sclerotinia sclerotiorum isolates of different geographic origin. Bot. Bull. Acad. Sin. 32:279-286.

Huzar-Novakowiski, J., Paul, P. A., and Dorrance, A. E. 2017. Host resistance and chemical control for management of Sclerotinia stem rot of soybean in Ohio. Phytopathology 107:937-949.

Kohn, L. M. 1979. Delimitation of the economically important pathogenic Sclerotinia species. Phytopathology 69:881-886.

Kora, C., McDonald, M. R., and Boland, G. J. 2005. Epidemiology of Sclerotinia ro of carrot caused by Sclerotinia sclerotiorum. Can. J. Plant Pathol. 27:245-258.

Kurle, J. E., Grau, C. R., Oplinger, E. S., and Mengistu, A. 2001. Tillage, crop sequence, and cultivar effects on Sclerotinia stem rot incidence and yield in soybean. Agron. J. 93:973-982.

Letham, D. B. 1975. Simulation of light of apothecial initial development of Sclerotinia sclerotiorum in soil. Soil Biol. Biochem. 8:385-389.

Madden, L. V., Hughes, G., and van den Bosch, F. 2007. Study of Plant Disease Epidemics. American Phytopathological Society, St. Paul, MN.

Matheron, M. E., and Porchas, M. 2005. Influence of soil temperature and moisture on eruptive germination and viability of sclerotia of Sclerotinia minor and S. sclerotiorum. Plant Dis. 89:50-54.

Merriman, P. R. 1976. Survival of sclerotia of Sclerotinia sclerotiorum in soil. Soil Biol. Biochem. 8:385-389.

Mila, A. L., and Yang, X. B. 2008. Effects of fluctuating soil temperature and water potential on sclerotia germination and apothecial production of Sclerotinia sclerotiorum. Plant Dis. 92:78-82.

Mueller, D. S., Bradley, C. A., Grau, C. R., Gaska, J. M., Kurle, J. E., and Pedersen, W. L. 2004. Application of thiophanate-methyl at different host growth stages for management of Sclerotinia stem rot in soybean. Crop Prot. 23:983-988.

Mueller, D. S., Dorrance, A. E., Derksen, R. C., Ozkan, E., Grau, C. R., Gaska, J. M., Hartman, G. L., Bradley, C. A., and Pedersen, W. L. 2002a. Efficacy of fungicides on Sclerotinia sclerotiorum and their potential for control of Sclerotinia stem rot of soybean. Plant Dis. 86:26-31.

Mueller, D. S., Harman, G. L., and Pedersen, W. L. 2002b. Effect of crop rotation and tillage system on Sclerotinia stem rot on soybean. Can. J. Plant Pathol. 24:450-456.

Nelson, K. A., Renner, K. A., and Hammerschmidt, R. 2002. Effects of protoporphyrinogen oxidase inhibitors on soybean (Glycine max L.) response, Sclerotinia sclerotiorum disease development, and phytoalexin production by soybean. Weed Technol. 16:353-359.

Pan, H., Xi, J., Liu, W., Wang Q., and Li, H. 2001. Optimal stage and threshold of the control Sclerotinia rot. Acta Phytophylac. Sin. 4:299-302.

Peltier, A. J., Bradley, C. A., Chilvers, M. I., Malvick, D. K., Mueller, D. S., Wise, K. A., and Esker, P. D. 2012. Biology, yield loss and control of Sclerotinia stem rot of soybean. J. Integr. Pest Manage. 3:B1-B7.

Phillips, A. J. L. 1986. Carpogenic germination of sclerotia of Sclerotinia sclerotiorum after periods of conditioning in soil. J. Phytopathol. 116:247-258.

Ramsey, G. B. 1925. Sclerotinia species causing decay of vegetables under transit and market conditions. J. Agric. Res. 31:597-632.

Rueden, C., Dietz, C., Horn, M., Schindelin, J., Northan, B., Berthold, M., and Eliceiri, K. 2016. ImageJ Ops (software). Online publication. http://imagej.net/ImageJ_Ops

Saito, I. 1977. Studies on the maturation and germination of sclerotia of Sclerotinia sclerotiorum (Lib.) De Bary, a causal fungus of bean stem rot. Rep. Hokkaido Prefect. Agric. Exp. Stn. 26

Steadman, J. R., Coyne, P. D., and Cook, G. E. 1973. Reduction of severity of white mold disease on great northern beans by wider spacing and determinate plant growth habit. Plant Dis. Rep. 57:1070-1071.

Steadman, J. R., Marcinkowska, J., and Rutledge, S. 1994. A semi-selective medium for isolation of Sclerotinia sclerotiorum. Can. J. Plant Pathol. 16:68-70.

Sun, P., and Yang, X. B. 2000. Light, temperature, and moisture effects on apothecium production of Sclerotinia sclerotiorum. Plant Dis. 84:1287-1293.

Sutton, D. C., and Deverall, B. J. 1983. Studies on infection of bean (Phaseolus vulgaris) and soybean (Glycine max) by ascospores of Sclerotinia sclerotiorum. Plant Pathol. 32:251-261.

Willbur, J. F., Fall, M. L., Bloomingdale, C. A., Byrne, A. M., Chapman, S. A., Isard, S. A., Magarey, R. D., McCaghey, M. M., Mueller, B. D., Russo, J. M., Schlegel, J., Chilvers, M. I., Mueller, D. S., Kabbage, M., and Smith, D. L. 2018. Weatherbased models for assessing the risk of Sclerotinia sclerotiorum apothecial presence in soybean (Glycine max) fields. Plant Dis. 102:73-84.

Wunsch, M. 2014. Managing white mold in dry beans and soybeans: What we do and do not know. Online publication. North Dakota State University Agriculture and Extension. https://www.ag.ndsu.edu/ndsuag/gsearch?q=white $\% 20$ mold 